\title{
Findes der en global temperatur? - fundamentet for hele klimadebatten
}

Af lektor dr. scient Bjarne Andresen, Niels Bohr Institutet, Københavns Universitet

\section{Nej, det er fundamentalt termo-} dynamisk umuligt at definere en gennemsnitstemperatur af noget som helst. Denne kategoriske, og termodynamisk set ganske elementære, udtalelse har vakt en hel del furore, siden vi publicerede den for godt et år siden, for når der ikke findes en global gennemsnitstemperatur, hvordan kan den så være steget i nyere tid, og hvad med det videnskabelige grundlag for Kyotoprotokollen og andre store politiske tiltag, der som begrundelse henviser til en voksende global temperatur? Tjah, det vil jeg overlade til læserne selv at konkludere.

Jeg har to hovedpointer:

- Gennemsnit af intensive størrelser som temperatur har ingen termodynamisk mening.

- Gennemsnitsberegninger kan foretages på uendeligt mange måder.

\section{Ekstensive/intensive størrelser}

Størrelser, der beskriver et system, kan inddeles $i$ intensive og ekstensive med meget forskellig opførsel. Ekstensive størrelser vokser med systemets omfang og er fx vo-

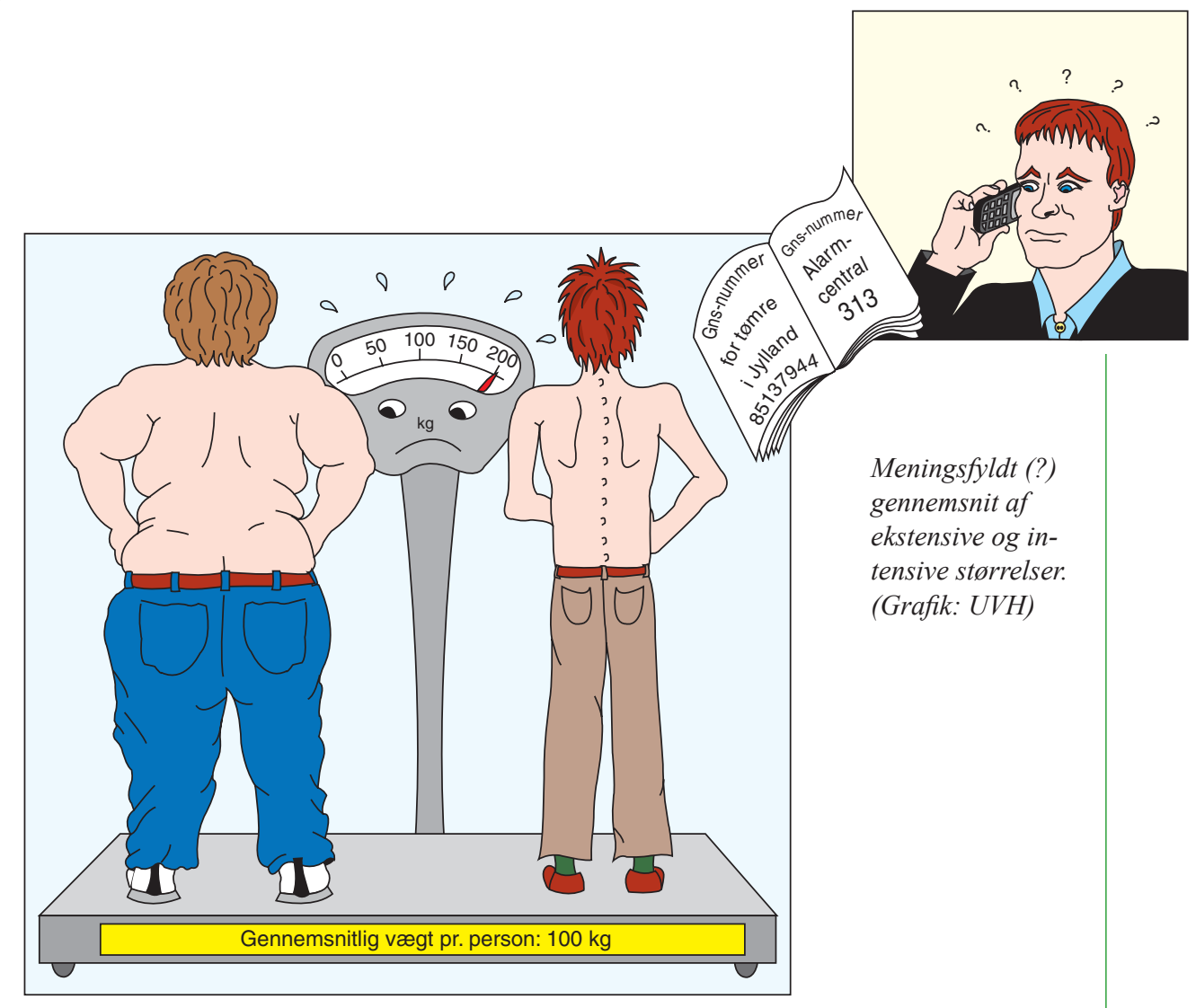

lumen, masse, vægt, energi, stofmængde, elektrisk ladning, formue, forbrug osv. Modsætningsvis angiver intensive størrelser intensiteter og er uafhængige af systemets omfang, fx temperatur, tryk, koncentration, elektrisk spænding, højde over Jordens overflade, vekselkurs, og pris.

En meget vigtig forskel mellem disse to typer er, at gennemsnit kun (meningsfyldt) kan udregnes af ekstensive størrelser. Mere generelt kan siges, at gennemsnit kun har mening, når summen har mening. To perso-

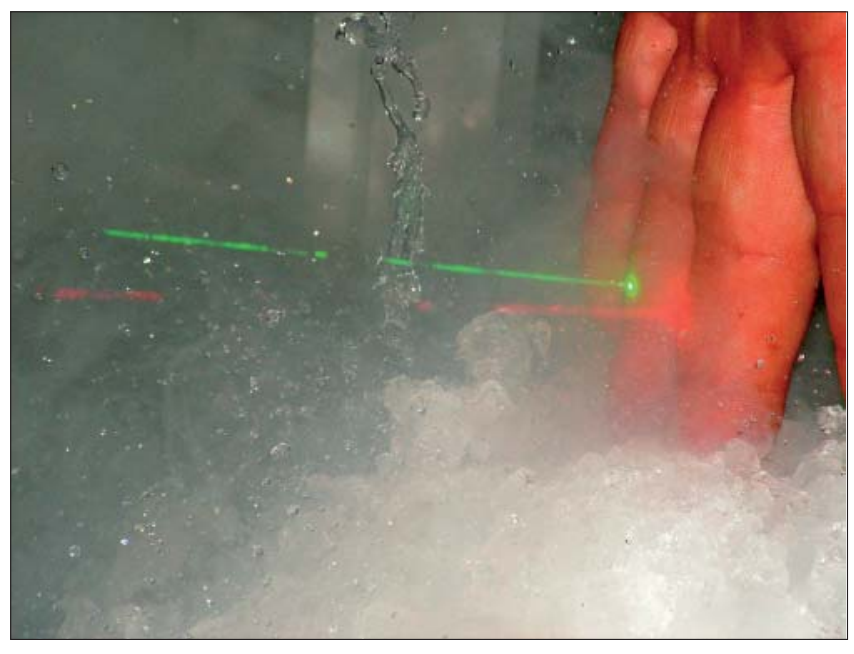

Fingre belyst af to laserstråler; for at synliggøre strålerne er der anvendt flydende nitrogen på is. (Foto: UVH) ners samlede vægt eller højde har mening, idet de sammen kan stille sig op på en vægt eller stille sig oven på hinanden. Vores samlede formue kunne samles på én bankkonto. Byens samlede vandforbrug kommer fra en fælles tank. Den gennemsnitlige vægt, højde osv. fås så ved at dividere med antallet af personer.

Derimod har det ingen mening at lægge intensiteter sammen som temperaturer, sødme af saftevand, priser osv. Det er lige så meningsfyldt som summen/gennemsnittet af vekselkurser eller telefonnumre. Selvfølgelig kan en computer kodes til at udregne også disse "gennemsnit", men hvad betyder fx det gennemsnitlige telefonnummer i telefonbogen? At et tal er muligt at udregne betyder ikke, at det har nogen mening.

\section{Hvad er temperatur?}

Temperatur er en ligevaegtsstørrelse, en intensitet på et bestemt tidspunkt på et bestemt sted eller i et homogent område. Matematisk set er den defineret som

$$
\mathrm{T} \equiv \frac{\partial \mathrm{U}}{\partial \mathrm{S}}
$$

hvor $\mathrm{U}$ er systemets indre energi og $\mathrm{S}$ er dets entropi. Den er altså en lokal kvalitet ved systemets energiindhold, uafhængig 
af systemets størrelse. Termodynamikere har forsøgt at konstruere en meningsfyldt og konsistent definition af temperatur også for ikke-ligevægtssystemer i mere end 50 år - uden held. Alle hidtidige forslag har resulteret $\mathrm{i}$ indre inkonsistenser. Indtil en meget indsigtsfuld termodynamiker kan løse dette problem, må vi nøjes med at benytte begrebet temperatur i enkelte punkter og for systemer i indre ligevægt.

Rent faktisk kan et homogent system eller et punkt udmærket have flere forskellige temperaturer på samme tid. Det er fx tilfældet i en laser, hvor den elektroniske frihedsgrad har en ekstremt meget højere temperatur end den translatoriske frihedsgrad (som er den, vi måler med et normalt termometer). Lyset, der kommer ud af laseren, har typisk en temperatur på $10^{11} \mathrm{~K}$, men vi brænder ikke fingrene hverken ved at stikke dem ind i lysstrålen eller ved at berøre laseren. De to frihedsgrader kobler ikke og har derfor hver deres temperatur.

\section{Temperaturfelter}

Dynamiske systemer, altså systemer ude af ligevægt evt. drevet af en ydre kraft, kræver et helt felt for hver intensiv variabel, $\mathrm{fx}$ $\mathrm{T}(\mathrm{x}, \mathrm{y}, \mathrm{z}, \mathrm{t})$, og kan på ingen måde repræsenteres af en enkelt variabel. Stort set alt i vores omgivelser (inklusive os selv) indeholder forskelle og dermed gradienter. Forskellige hjørner af mit kontor har forskellig temperatur, min hud og min lever har forskellig temperatur, og forskellige geografiske steder har forskellige temperaturer. Det er alle disse forskelle, der skaber klimaet og driver vinde, havstrømme osv.

En "gennemsnitstemperatur", hvordan man end kunne definere den korrekt, har ingen relevans for sådanne strømme. På den ene side kunne man forestille sig at hæve alle temperaturer i hele feltet med en konstant værdi. Det ville ikke ændre nogen gradienter og dermed heller ingen strømme, men slå igennem fuldt ud i "gennemsnittet". På den anden side kunne man forestille sig at ekvilibrere alle steder til netop den beregnede "gennemsnitstemperatur". Det ville per definition ikke ændre "gennemsnittet", men fjerne alle gradienter og dermed alle strømme. Endelig kunne man forestille sig den meget simple geometriske transformation at rotere hele det eksisterende temperaturfelt omkring en akse gennem Jordens centrum, fx en øst-vest akse. Hele feltet ville forblive uændret og dermed også "gennemsnittet", men klimaet langt fra.

\section{Betingelser for gennemsnit}

En mulig definition af gennemsnitstemperaturen for en samling af komponenter kunne være den temperatur, som det samlede system ville opnå ved at komme i indre ligevægt. Lad os for simpelheds skyld tage et system bestående af to lige store glas mælk, et varmt og et koldt med begyndelsestemperaturerne $T_{1}$ og $T_{2}$. Disse to glas mælk skal

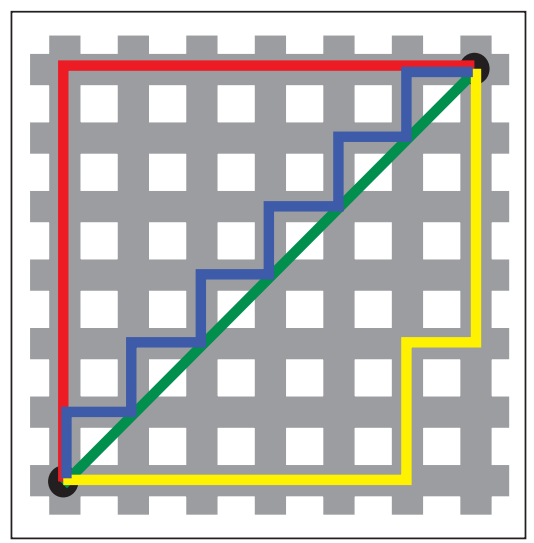

Manhattan kontra Euklidisk afstand:

Fire forskellige veje fører fra nederste venstre hjørne til øverste højre. Tre af dem, den røde, blå og gule, har efter $d^{l}$ metrikken den samme loengde 12.

De røde, blå og gule linier viser Manhattan-afstanden. Den grønne linie viser den Euklidiske afstand og følger $d^{2}$-metrikken med loengden

$$
6 \times \sqrt{2} \approx 8,48
$$

(Grafik: UVH modificeret efter illustration fra http: |limages.google.com)

Kort over Manhattan. (Kilde: http:॥ www.aaccessmaps.com $\mid$ show $\mid$ map $\mid$ manhattan)

så bringes i ligevægt for, at vi kan finde deres "gennemsnitstemperatur". Det kan gøres på mange måder, så lad os vælge noget simpelt. Vi kan simpelthen hælde de to glas sammen. Ser vi bort fra alle mulige irrelevante tab, får blandingen sluttemperaturen

$$
\mathrm{T}_{\mathrm{eq}}=\frac{\mathrm{T}_{1}+\mathrm{T}_{2}}{2} \text {, }
$$

det aritmetiske gennemsnit. Denne blanding kan ikke gå baglæns, den er irreversibel. Modsætningsvis kunne vi gennem en passende maskine (fx en Carnot maskine) lade de to glas komme til ligevægt på en tabsfri måde, således at processen kunne bringes til at gå baglæns. I så fald bliver sluttemperaturen

$$
\mathrm{T}_{\mathrm{eq}}=\sqrt{\mathrm{T}_{1} \cdot \mathrm{T}_{2}},
$$

det geometriske gennemsnit (som i øvrigt altid er lavere end det aritmetiske). Den første blandingsproces er energetisk isoleret, den anden entropisk isoleret, og de leder til vidt forskellige resultater. Med andre ord betyder betingelserne, under hvilke ligevægten fremkommer og dermed den fælles temperatur, alt.
Et andet eksempel relaterer sig til, hvilken metrik der anvendes under udregningen. Manhattan er bl.a. kendt for sit meget regulære gadenet. Skal man fra punkt A til punkt $\mathrm{B}$, må man til fods følge dette gadenet og mindst gå afstanden, der er summen af ændringen i x-koordinat plus ændringen $\mathrm{i}$ y-koordinat

$$
\mathrm{d}=|\mathrm{x}|+|\mathrm{y}|,
$$

den såkaldte $\mathrm{d}^{1}$-metrik eller Manhattan-metrik. En fugl behøver ikke at følge gaderne og kan flyve direkte fra A til B, en kortere afstand udmålt efter Pythagoras

$$
d=\sqrt{x^{2}+y^{2}},
$$

kaldet en $\mathrm{d}^{2}$-metrik. Alle mulige andre eksponenter fra $-\infty$ til $+\infty$ kan selvfølgelig også komme på tale.

Forskellige fysiske processer implicerer forskellige metrikker. Simpel varmeledning beskrives af $\mathrm{d}^{1}$-metrikken, altså simple forskelle i temperatur. Energioverførsel gennem stråling kræver $\mathrm{d}^{4}$-metrik, altså forskelle i 4. potens af temperaturerne. For at benytte den rigtige metrik skal man have en solid fysisk grund. Er denne fysiske grund 
ikke konkret udledt for den forhåndenværende proces, er alle potenser a priori lige gode, og så har vi et problem med tydning af data.

\section{Sammenligning af temperaturer}

På den øverste figur har jeg skitseret intervallerne for de temperaturer, der findes på hhv. Mars, Jorden og Venus. Som det ses, er selv det koldeste punkt på Venus varmere end det varmeste punkt på Jorden. Alle metrikker vil give dette resultat, og det er derfor problemfrit at kalde Venus varmere end Jorden. Mars' og Jordens temperaturintervaller overlapper derimod. Det er derfor ikke entydigt, hvilken af de to planeter, der er den varmeste. Resultatet afhænger af, hvilken metrik man har brugt til sammenligningen, og i mangel af en fundamental fysisk grund er den ene metrik lige så "rigtig" som den anden.

\section{Temperatur som proxy for energi}

"Jamen, når vi kalder det den globale gennemsnitstemperatur, mener vi ikke egentlig temperatur, kun temperatur som et mål for energi", hører man ofte. Fair nok. Naturvidenskabelig forskning er fuld af sådanne proxyer, altså en erstatning for det, man egentlig gerne ville have målt. Det måske mest billedlige eksempel er kulminearbejderne, der tog kanariefugle med ned i minerne. Når den lå på bunden af buret, var det på tide at komme op, for så var der kulilte $i$ luften.

Når vi måler en temperatur, er det heller ikke via den grundlæggende definition. I et søjletermometer måler vi i virkeligheden længden af kviksølvstrengen, som igen relaterer sig til kviksølvets volumenudvidelse med temperaturen. I elektroniske termometre måler man spændingsforskellen eller modstandsændringen i føleren. I alle tilfælde har man dog meget omhyggeligt relateret den målte størrelse til temperaturen, både gennem teoretiske overvejelser af den involverede fysiske proces og ved empirisk kalibrering under strikte betingelser. En sådan omhyggelig kalibrering, hverken teoretisk eller empirisk, af de gængse metoder til udregning af "den globale gennemsnitstemperatur" som proxy for energiindholdet i Jordens overfladelag eksisterer ikke. Disse opskrifter er derfor ikke videnskabeligt gyldige erstatninger for energiindholdet.

Rent faktisk passer pengene heller ikke. Lad os igen tage et ekstremt simpelt system bestående af en ideal gas af $\mathrm{N}$ partikler med energien $U$, volumen $V$ og entropi S. Den totale tilstandsligning for denne gas er

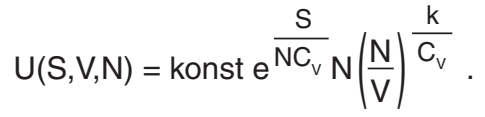

De fleste kender nok snarere den simplere udgave

$$
\mathrm{U}(\mathrm{N}, \mathrm{T})=\frac{3}{2} \mathrm{NkT}
$$

\section{Temperaturintervaller for Mars, Jorden og Venus}

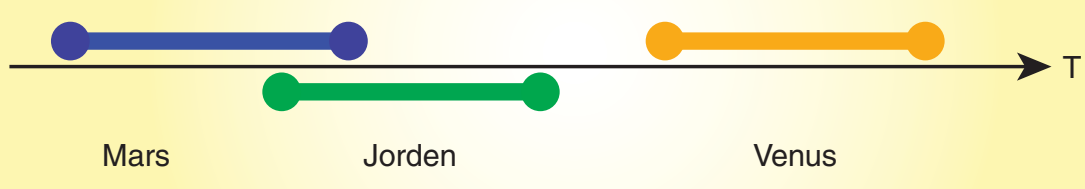

Venus er klart varmere end Jorden og Mars. Men er Jorden varmere end Mars? Lave prcecisionskrav tillader mere lemfceldig omgang med gennemsnit. (Grafik: UVH modificeret efter forfatterens oplocg)

men det er kun et specialtilfælde af den fulde tilstandsligning, nemlig for fastholdt volumen. Desuden er $\mathrm{S}$ transformeret til $\mathrm{T}$. En ækvivalent udgave i tæthederne $\mathrm{u}=\mathrm{U} / \mathrm{V}$ og $n=N / V$ er

$$
\mathrm{u}(\mathrm{n}, \mathrm{T})=\frac{3}{2} \mathrm{nkT} .
$$

En lille relativ ændring af energitætheden du/u kan så skrives som

$$
\frac{d u}{u}=\frac{d P}{P}=\frac{d n}{n}+\frac{d T}{T} .
$$

Da den relative trykvariation hen over Jorden ikke overstiger $5 \%$, mens den relative temperaturvariation nærmere er $20 \%$, ses det, at partikeltætheden ikke kan være bare tilnærmelsesvist konstant og dermed heller ikke volumenet, som antaget ved reduktionen fra 3 variable $(\mathrm{S}, \mathrm{V}, \mathrm{N})$ til $2,(\mathrm{~N}$, $\mathrm{T})$. Skal temperaturen bruges som proxy for energien, skal vi af med yderligere en variabel for at komme til U(T), dvs. både volumenet og partikelantallet er nu antaget konstant $i$ ethvert flow-element $i$ atmosfæren. Det er nok ikke særligt realistisk.

Alle analyser af fysiske systemer er foretaget under visse antagelser, fx konstans af visse størrelser. Resultatet af analysen afhænger essentielt af, hvad der antages konstant. En central termodynamisk størrelse er varmekapaciteten, som bl.a findes i de to varianter $\mathrm{C}_{\mathrm{v}}$ og $\mathrm{C}_{\mathrm{p}}$ for hhv. konstant volumen og konstant tryk; de er klart forskellige. I tilfældet $\mathrm{C}_{\mathrm{p}}$ går ikke al den indkommende varme til at hæve temperaturen af systemet, en del går til ekspansion af gassen mod den konstante temperatur. Da dette bidrag er proportionalt med opvarmningsbidraget, kan det lægges til $\mathrm{C}_{\mathrm{V}}$ og give $\mathrm{C}_{\mathrm{p}}=\mathrm{C}_{\mathrm{V}}+\mathrm{k}$. Også andre varmekapaciteter under antagelse af andre ligevægtssituationer benyttes ind imellem, $\mathrm{fx}_{\mathrm{C}} \mathrm{C}_{\mathrm{r}}$ under opretholdt væskegas ligevægt i forbindelse med destillation. Brugen af en "global temperatur" lever ikke op til denne stringens mht. definition af den antagne ligevægtsproces.

\section{Matematiske gennemsnit}

I termodynamikken findes mange relevante gennemsnit, $\mathrm{fx}$

termodynamisk temperatur:

$$
\mathrm{R}_{-1}\left(\mathrm{~T}_{1}, \mathrm{~T}_{2}\right)=\left(\frac{\mathrm{T}_{1}^{-1}+\mathrm{T}_{2}^{-1}}{2}\right)^{-1}
$$

varmeledning:

$$
\mathrm{R}_{1}\left(\mathrm{~T}_{1}, \mathrm{~T}_{2}\right)=\left(\frac{\mathrm{T}_{1}+\mathrm{T}_{2}}{2}\right)
$$

Pythagoras:

$$
\mathrm{R}_{2}\left(\mathrm{~T}_{1}, \mathrm{~T}_{2}\right)=\left(\frac{\mathrm{T}_{1}^{2}+\mathrm{T}_{2}^{2}}{2}\right)^{1 / 2}
$$

stråling:

$$
R_{4}\left(T_{1}, T_{2}\right)=\left(\frac{T_{1}^{4}+T_{2}^{4}}{2}\right)^{1 / 4}
$$

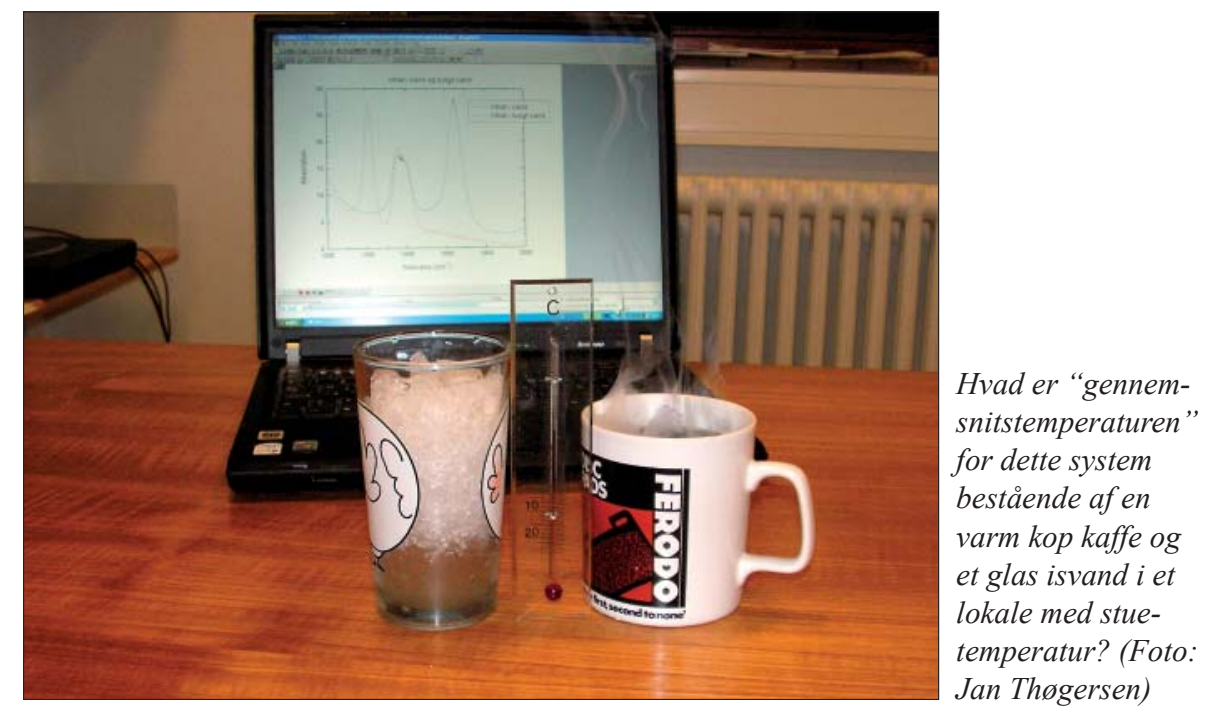


Antag nu, at vi anbringer en varm kop kaffe og et glas isvand $i$ et lokale med stuetemperatur. Hvad er den "gennemsnitlige temperatur" af dette system, og ikke mindst hvordan udvikler den sig med tiden, mens de to forfriskninger kommer i ligevægt med lokalet? For et vist valg af starttemperatur, masser osv. findes de fire "gennemsnitstemperatur"-forløb i figuren øverst til højre, alle selvfølgelig med den samme ligevægtstemperatur. Læg mærke til, at vi har beskrevet det samme fysiske forløb, men med 4 forskellige gennemsnitsmetoder. Som det tydeligt ses, siger to af metoderne, at lokalets "gennemsnitlige temperatur" er steget undervejs, to at den er faldet. Hverken forsøget eller beregningerne er fejlbehæftede, men det er fortolkningen som "den gennemsnitlige temperatur".

For nu ikke udelukkende at tale om forsimplede modeller har vi taget temperaturmålinger fra 12 vidt forskellige steder på Jorden for perioden 1979-2000, publiceret af Goddard Space Institute, og analyseret deres trend med en bred vifte af gennemsnit af typen brugt lige ovenfor, nemlig med gennemsnittene $\mathrm{R}_{-125}$ til $\mathrm{R}_{125}$. Igen de samme primærdata med forskellige gennemsnitsmetoder (figuren midtfor). Resultatet af analysen, trenden i temperaturudvikling for denne (lidt grove) dækning af Jordens overflade, ses på figuren nederst, hvor abscissen er typen af gennemsnit (potensen r), ordinaten den resulterende temperaturændrings trend i K per årti. Det fremgår, at for de allerfleste gennemsnitsmetoder har vi øjensynligt haft en betydelig afkøling i den pågældende periode. Kun for ganske få parameterværdier ser det ud som en opvarmning. Det hænger ikke sammen.

Problemet er, at der mangler fysiske argumenter for at vælge en bestemt gennemsnitsparameter værdi (eller en helt tredie gennemsnitsmetode). Henvisninger til, at "vi plejer", eller "sædvanligt gennemsnit" (altså $\mathrm{R}_{1}$ ) holder simpelthen ikke vand videnskabeligt set.

\section{Alt det, jeg ikke siger}

Læg vel mærke til, at jeg på intet tidspunkt påstår, at klimaet ikke ændrer sig, at vi mennesker bare skal give pokker i naturen og svine løs, eller at alle klimaforskere ikke kender deres metier. Som argumenteret ovenfor forventer jeg blot, at også klimaforskning lever op til almindelig grundvidenskabelig stringens, som bl.a. betyder, at

- alle størrelser skal være omhyggeligt definerede og i overensstemmelse med fysikkens fundamentale principper. Man skal altså fx ikke bruge navnet "temperatur" om noget, der ikke er en temperatur, da det har store implicitte konsekvenser.

- valget af analysemetode er præcist fysisk begrundet, ikke bare "vi plejer". Kan en sådan fysisk begrundelse ikke præsenteres, er metoden uanvendelig.

Tidsudviklingen af "den gennemsnitlige temperatur" for et system bestående af et glas isvand og en kop varm kaffe $i$ et lokale under anvendelse af gennemsnitsmetoderne $R_{-l}, R_{l}, R_{2}$ og $R_{4}$. To af beskrivelserne konkluderer en gradvis gennemsnitlig opvarmning, de to andre en afkoling - for det samme fysiske system. (Grafik: UVH modificeret efter forfatteren $m$. . $l$.)

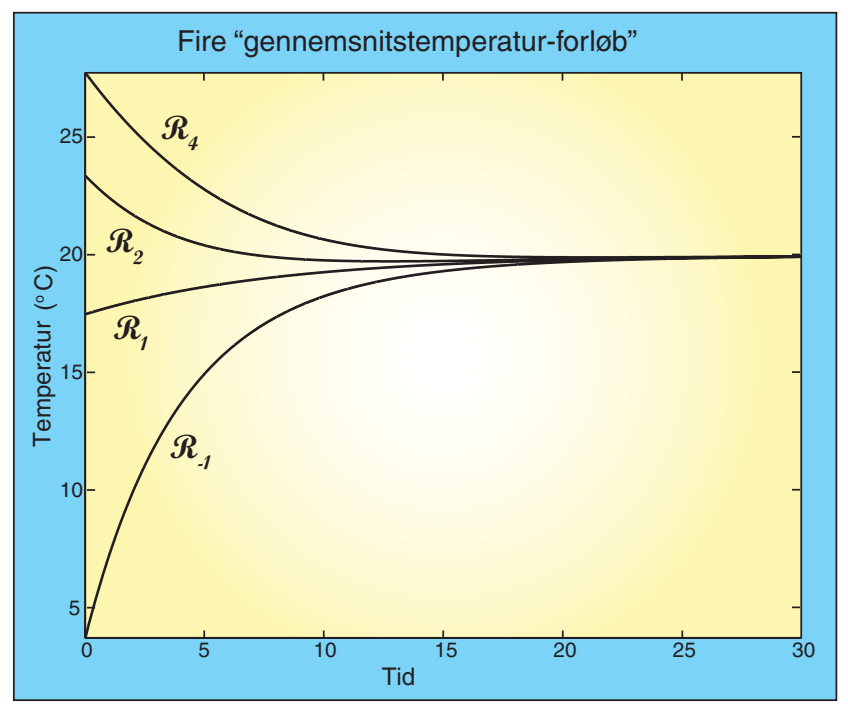

De 12 målestationer spredt over Jorden, hvorfra data er samlet til figuren nedenfor i perioden 19792000. (Kilde: Goddard Space Institute)

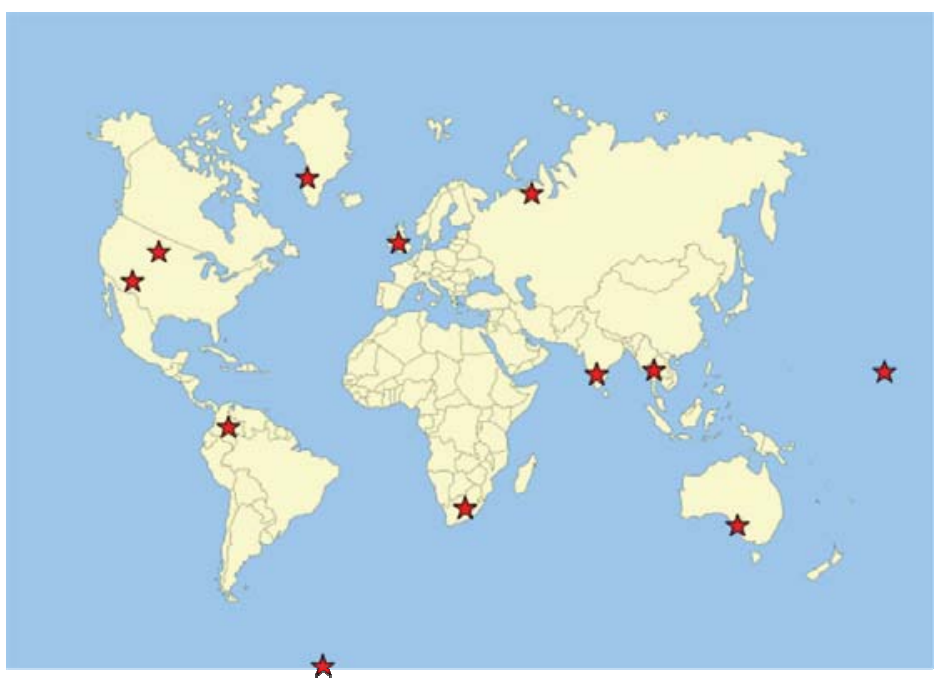

Den "gennemsnitlige" temperatur-trend for de 12 målestationer vist på figuren lige ovenfor $i$ enheden K/årti, når gennemsnittet er beregnet med potensen $r$ i udtrykkene $R_{r}$ givet tidligere. Det "scedvanlige" aritmetiske gennemsnit $r=1$ er fremhoevet med den stiplede linie. Om Jorden efter disse målinger opvarmes eller afkøles, afhoenger tydeligvis af den gennemsnitsmetode, der anvendes $i$ analysen! (Grafik: UVH modificeret efter forfatteren m.fl.)

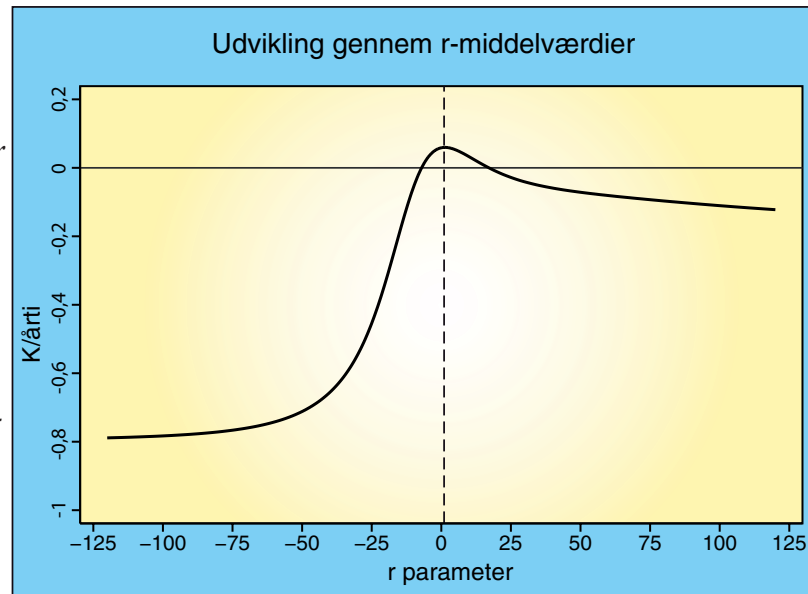

Den lodrette stiplede linie angiver lineært gennemsnit

- alle fortolkninger er rationelle, uden emotionelt indhold, og ikke mere vidtgående end data med deres usikkerheder kan garantere.

Det er imponerende, at så simple fundamentale principper kan skabe så stort postyr.
Reference:

C. Essex, R. McKitrick, B. Andresen: Does a Global Temperature Exist?; J. Non-Equil. Thermod. 32, 1-27 (2007). 